\title{
Qualidade de sementes de soja convencional e Roundup Ready (RR), produzida para consumo próprio e comercial
}

\section{Seeds quality of conventional and Roundup Ready (RR) soybeans produced for own and commercial consumption}

\author{
Dirceu de Melo ${ }^{1 *}$, William Terroso de Mendonça Brandãoํㅡㄴ Lúcia Helena Pereira Nóbrega² e \\ Ivan Werncke ${ }^{3}$
}

${ }^{1}$ Universidade Tecnológica Federal do Paraná, Câmpus Medianeira, Av. Brasil, 4232 CEP 85884-000 - Caixa Postal 271, Medianeira, Paraná, Brasil; 2 Centro de Ciências Exatas e Tecnológicas - Unioeste - CCET, Rua Universitária, 1619 CEP 85819-110, Cascavel, Paraná, Brasil;

3 Universidade Tecnológica Federal do Paraná, Câmpus Medianeira, Av. Brasil, 4232 CEP 85884-000 - Caixa Postal 271, Medianeira, Paraná, Brasil. (*E-mail: dirceu@utfpredu.br)

http://dx.doi.org/10.19084/RCA15072

Recebido/received: 2015.06.16

Aceite/accepted: 2015.10 .01

\section{R E S U M O}

A garantia de sementes com elevado vigor e boa qualidade é fundamental para o sucesso de qualquer cultura. Sementes com baixo vigor podem apresentar dificuldades na germinação e emergência em campo, sob condições não favoráveis, como a falta de umidade ou baixas temperaturas. Portanto, os produtores, na tentativa de reduzir custos de produção, têm separado grãos da safra produzida para serem utilizados como sementes e isso tem sido cada vez mais frequente. Assim, este trabalho teve como objetivo avaliar o potencial fisiológico de sementes de soja Roundup Ready com sementes convencionais, e comparar sementes "salvas", produzidas por um produtor com sementes comerciais. As sementes foram caracterizadas em laboratório (pureza, massa de mil sementes e teor de água), submetidas a testes de vigor (envelhecimento acelerado, teste de frio e condutividade elétrica), teste de germinação, emergência em areia, índice de velocidade de emergência, crescimento de plântulas, comprimento de raízes e parte aérea das plântulas e matéria fresca e seca. Foi possível identificar maior pureza nas sementes comerciais do que nas sementes "salvas". Os lotes das cultivares convencionais apresentaram potencial fisiológico superior às cultivares de soja Roundup Ready, porém, entre as sementes "salvas" e comerciais não houve diferença quanto ao vigor.

Palavras-chave: germinação, pureza, sistema de produção, teste de vigor.

\begin{abstract}
A B S T R A C T
The guarantee of seeds with high vigor and good quality is the most important characteristic for the success in soybean cropping. Seeds with low vigor may show some difficulty on germination and field emergence, mainly under adverse conditions, such as moisture deficiency or low temperatures. Thus, this study aimed at evaluating the physiological potential of Roundup Ready (RR) and conventional soybean seeds, 'saved' by a farmer as well as commercial seeds. Nevertheless, some farmers, in an attempt to reduce production costs, have already separated cropped grains produced to be used as seeds and it has been increasingly common. So, this trial aimed at evaluating the physiological potential of Roundup Ready soybean seeds with conventional seeds, and compare the 'saved' seeds, produced by a farmer with commercial seeds. The seeds were characterized in the laboratory (purity, mass of thousand seeds and moisture content). Vigor (accelerated aging, cold test and electrical conductivity test), germination test, emergence on sand, emergence speed index, seedling growth, roots and shoots length of seedlings as well as fresh and dry matter were determined. It was possible to identify that the commercial seeds showed higher purity when compared to the saved ones. Plots of conventional cultivars showed higher physiological potential, and there was no difference concerning the vigor between the 'saved' seeds and commercial ones.
\end{abstract}

Key words: germination, purity, production system, vigor test. 


\section{INTRODUÇÃO}

O estabelecimento de culturas com população adequada de plantas é um dos fatores que mais contribui para assegurar o sucesso da produção e obtenção de altos rendimentos. A utilização de sementes com baixo vigor poderá tornar necessária nova semeadura, resultando em prejuízos (Pinto et al., 2007). O uso de sementes de alto vigor assegura adequada população de plantas, sob ampla variação de condições ambientais de campo (Scheeren et al., 2010). O elevado vigor de sementes é importante para se obter germinação uniforme, com estande ideal de plantas (Oliveira et al., 2009).

O uso de sementes de baixa qualidade, aliado à ocorrência de condições ambientais adversas (baixas temperaturas e períodos de estiagem) por ocasião da semeadura, pode resultar em baixa percentagem de germinação e menor velocidade de emergência das plantas. Por outro lado, as sementes consideradas de alto vigor, normalmente apresentam germinação mais rápida e uniforme, sendo capaz de suportar melhor as adversidades do ambiente (Lopes et al., 2002).

$\mathrm{O}$ processo de produção de sementes exige tecnologias desde a escolha da cultivar até a comercialização, que abrangem seleção da área, uso de variedades recomendadas, semeadura em épocas estabelecidas, acompanhamento do desenvolvimento vegetativo, práticas culturais, tratamentos fitossanitários, determinação do momento ideal de colheita e limpeza adequada dos equipamentos de transporte e beneficiamento (Marcondes et al., 2005; Sinício et al., 2009).

Os avanços tecnológicos da agricultura colocam no mercado cultivares cada vez mais produtivas, mais adaptadas e com materiais genéticos de alto potencial produtivo (Torres et al., 2015), o que influencia no aumento do rendimento (Rigon et al., 2012). Estas tecnologias podem contribuir em mais de $50 \%$ no aumento da produtividade no cultivo de grãos, sendo um benefício que o produtor pode deixar de aproveitar quando utiliza sementes próprias, de má qualidade, produzidas fora dos padrões exigidos, as popularmente chamadas sementes crioulas ou sementes "salvas" (Tozzo e Peske, 2007).

As sementes de soja originadas do melhoramento genético podem ser chamadas convencionais, quando não possuem alteração na cadeia genética, e as transgênicas com tecnologia RR - Roundup Ready, são aquelas que o material genético foi manipulado de modo a favorecer alguma característica desejada, no caso, a resistência ao glifosato - ( $N$-fosfonometil glicina). Este é um herbicida sistêmico de ação total, não-seletivo, pós-emergente, amplamente utilizado na agricultura (Bervald et al., 2010).

Na produção de soja convencional, em média, são necessárias duas ou três aplicações de defensivos em mistura, aumentando, consequentemente, o custo de mão-de-obra e matéria prima durante o processo produtivo. No cultivo da soja Roundup Ready (RR), a aplicação de glifosato pós-emergente, permite controlar as plantas invasoras, e normalmente é feita apenas uma vez, durante o ciclo de produção (Furlaneto et al., 2008). No entanto, o uso de plantas geneticamente modificadas Roundup Ready (RR), pode diminuir o potencial fisiológico das sementes.

O vigor caracteriza-se pela habilidade de determinado lote de sementes estabelecer plântulas normais em condições de campo (Moterle et al., 2011). Os testes de vigor têm uso cada vez mais rotineiro, pela indústria de sementes para determinação do potencial fisiológico e, dentre os mais utilizados, estão envelhecimento acelerado e condutividade elétrica (Santos et al., 2011). Pesquisas realizadas envolvendo esses testes (Silva et al., 2008; Carvalho et al., 2009) mostraram que ambos são satisfatórios na avaliação do potencial fisiológico de sementes de soja (Santos et al., 2011). O teste de condutividade elétrica baseia-se no fato de que o vigor está diretamente relacionado com a integridade do sistema de membranas celulares (Milani et al., 2012).

Assim, este trabalho teve como objetivo avaliar o potencial fisiológico de sementes de soja Roundup Ready (RR) e sementes convencionais, e comparar lotes de sementes "salvas" (produzidas por um produtor) com lotes de sementes comerciais (produzida por unidade produtora de sementes), além de caracterizar os lotes em laboratório por meio de testes de vigor e identificar os lotes mais vigorosos e de maior pureza.

\section{MATERIAL E MÉTODOS}

O trabalho foi desenvolvido no Laboratório de Avaliação de Sementes e Plantas (LASP) do Centro de Ciências Exatas e Tecnológicas da Universidade 
Estadual do Oeste do Paraná (UNIOESTE), Campus de Cascavel.

Sete lotes de sementes de soja (Glycine max) foram avaliados, sendo três de sementes "salvas" por um produtor da região e quatro lotes comerciais produzidas por uma unidade produtora de sementes. Os lotes de sementes "salvas" foram: lote $1 \mathrm{NK}$ - 1059 (V-Top) RR; lote 2: NK - 7059 (V-Max) RR; lote 3: NK - 7059 (V-Max) convencional. Os lotes comerciais foram: lote 1: NK - 1059 (V-Top) RR; lote 2: NK - 7059 (V-Max) RR; lote 3: CD - 215 RR e lote 4: CD - 215 convencional. As cultivares comerciais foram adquiridas junto ao setor sementeiro da Cooperativa Lar de Medianeira, no mês de setembro de 2012, época de comercialização das sementes aos produtores, para a semeadura da safra 2012/2013. As amostras dessas sementes já tinham sido avaliadas pela empresa e estavam aptas para semeadura. Estas sementes foram produzidas na safra 2011/2012, no município de Xanxerê, região Oeste de Santa Catarina, onde estão localizados os produtores de sementes da Cooperativa Lar, a qual faz todo o acompanhamento da produção, colheita, armazenamento e classificação das mesmas.

As cultivares "salvas" foram produzidas no município de Medianeira - Pr. A semeadura ocorreu em 21 de janeiro e a colheita em 31 de maio de 2012, sendo o cultivo caracterizado como soja "safrinha". Uma das principais vantagens deste tipo de cultivo é a coincidência da maturação e colheita com períodos climáticos mais favoráveis à obtenção de sementes de soja de melhor qualidade fisiológica (Lima et al., 2009).

A colheita foi com a colhedora MF 5650, com sistema de saca-palhas. Após, as sementes foram descarregadas em "big bags" e levadas ao sistema de limpeza e classificação. O beneficiamento foi em mesa densimétrica e a padronização por sistema de rotor, com variação máxima de $1 \mathrm{~mm}$ de diâmetro. Na sequência da padronização, as sementes foram colocadas em bolsas de $40 \mathrm{~kg}$ e acomodadas no galpão na propriedade.

Para avaliação do potencial fisiológico, os lotes foram caracterizados (pureza, massa de mil sementes e teor de água) e submetidos a testes de vigor (envelhecimento acelerado, teste de frio e condutividade elétrica). Nos lotes foram ainda realizados os testes de germinação, emergência em areia, índice de velocidade de emergência (IVE), crescimento de plântulas, comprimento de raízes e parte aérea das plântulas, matéria fresca e seca. Os procedimentos utilizados para a condução de cada teste estão descritos a seguir:

Pureza: foi realizado segundo a metodologia da RAS (Brasil, 2009), e consideradas puras todas as sementes e/ou unidades de dispersão pertencentes à espécie em exame, declarada pelo requerente, ou como sendo a predominante na amostra, incluindo todas as variedades botânicas e cultivares da espécie. As amostras foram separadas em quatro subamostras de $100 \mathrm{~g}$, de cada lote. Posteriormente, foram separadas manualmente em sementes puras, trincadas, de outras cores e enrugadas. Após a separação, as frações foram pesadas em balança de precisão 0,001g e os valores expressos em percentagem.

Massa de mil sementes: a partir das sementes puras separadas manualmente, foram pesadas quatro repetições de 100 sementes cada, de cada lote. Os valores foram expressos em massa de mil sementes (Brasil, 2009).

Teor de água e teor de água após o envelhecimento acelerado: pelo método da estufa a $105 \pm 3{ }^{\circ} \mathrm{C}$ por 24 horas, utilizando-se duas repetições de \pm 5 gramas de sementes de cada lote (Brasil, 2009). Os resultados foram expressos em percentagem (base úmida).

Envelhecimento acelerado: 250 sementes de cada lote foram distribuídas em camada única e uniforme sobre telas de inox e colocadas em caixas de germinação tampadas $(11 \times 11 \times 3,5 \mathrm{~cm})$, com 40 $\mathrm{mL}$ de água destilada ao fundo, sem que as sementes entrassem em contato com a água. Estas foram mantidas em câmara de envelhecimento a $41{ }^{\circ} \mathrm{C}$ por 48 horas (Marcos Filho, 1999). Seguidamente, quatro repetições de 50 sementes envelhecidas foram submetidas ao teste de germinação (substrato papel - Brasil, 2009), sendo a avaliação realizada no quinto dia após a semeadura (Santos et al., 2011). Os resultados foram expressos em percentagem de plântulas normais de cada lote.

Teste de frio: quatro subamostras de 50 sementes fisicamente puras, de cada lote, foram distribuídas em papel "germitest" umedecido com 2,5 vezes a sua massa com água destilada e enrolados, permanecendo por cinco dias em câmara tipo BOD, dentro de sacos plásticos a $10^{\circ} \mathrm{C}$ de acordo com Schuab 
et al. (2002). Na sequência, os sacos foram abertos e os rolos colocados em germinador a $25^{\circ} \mathrm{C}$, por quatro dias, conforme metodologia descrita por Barros et al. (1999). Os resultados foram expressos em percentagem de plântulas normais de cada lote.

Condutividade elétrica: quatro subamostras de 50 sementes, fisicamente puras de cada lote, foram pesadas em balança de precisão 0,001g. Em seguida, as sementes foram imersas em $75 \mathrm{~mL}$ de água deionizada e mantidas em câmara tipo BOD a 25 ${ }^{\circ} \mathrm{C}$, por $24 \mathrm{~h}$. Após a embebição, foi determinada a condutividade elétrica da solução utilizando condutivímetro de bancada marca Tecnal modelo Te$\mathrm{c}-4 \mathrm{MP}$, e os resultados expressos em $\mu \mathrm{Scm}^{-1} \mathrm{~g}^{-1}$. O teste foi conduzido conforme descrito por Vieira e Krzyzanowski (1999).

Índice de velocidade de emergência (IVE): o teste foi conduzido contando o número de plântulas emergidas, no teste de emergência em areia, anotando-se de 24 em 24 horas, as plântulas que apresentavam cotilédones acima da superfície do substrato, do quarto até o oitavo dia, sempre no mesmo horário (Nakagawa, 1999). O IVE foi calculado empregando-se a fórmula proposta por Maguire (1962). Os resultados foram expressos em número de plantas emersas por dia.

Germinação (substrato papel): quatro subamostras de 50 sementes fisicamente puras, de cada lote, foram distribuídas em papel "germitest" umedecidas com 2,5 vezes a sua massa com água destilada e após, foram enroladas e dispostas no germinador a $25{ }^{\circ} \mathrm{C}$ e umidade relativa em torno de $100 \%$, por oito dias (Brasil, 2009). Os resultados foram expressos em percentagem de plântulas normais de cada lote.

Crescimento de plântulas: quatro subamostras de 20 sementes fisicamente puras, de cada lote, foram distribuídas sobre uma linha traçada no terço superior do papel substrato em fileira, sendo direcionada a ponta da radícula para baixo, sobre folhas de papel "germitest" umedecidas com 2,5 vezes a sua massa com água destilada e após, foram cobertas com uma terceira folha e enroladas e dispostas no germinador a $25^{\circ} \mathrm{C}$ e humidade relativa em torno de $100 \%$, durante oito dias (Nakagawa, 1999). O comprimento das plântulas consideradas normais foi determinado ao final do oitavo dia, com auxílio de régua graduada. Os resultados foram expressos em mm, pela média das plântulas.
Emergência em areia: quatro subamostras de 50 sementes fisicamente puras, de cada lote, foram distribuídas a dois centímetros de profundidade, em caixas plásticas (com volume de $3 \mathrm{~L}$ ) contendo areia de textura média e umedecida com água destilada até atingir $60 \%$ da capacidade de retenção, com regas diárias após a implantação do teste. As caixas foram mantidas em laboratório, a $25^{\circ} \mathrm{C}$. A avaliação foi realizada no oitavo dia após a instalação do teste (Brasil, 2009). Os resultados foram expressos em percentagem de plântulas normais.

Comprimento de raízes e parte aérea das plântulas: no final do teste de emergência em areia, foi efetuada a medida das partes das plântulas emergidas (parte aérea e raiz), de dez plântulas normais, com auxílio de régua graduada, e os resultados foram expressos em milímetros (Vanzolini e Carvalho, 2002; Bervald et al., 2010).

Massa fresca e seca: a massa fresca das plântulas de soja foi dividida em duas partes, parte área e de raiz, obtidas a partir do teste de crescimento de plântulas e do teste de emergência em areia. As amostras de massa fresca foram pesadas em balança de precisão 0,001 g sendo utilizadas 20 plântulas normais de cada repetição após a avaliação do teste de crescimento de plântulas e do teste de emergência em areia. A seguir, as plântulas foram levadas à estufa a $65^{\circ} \mathrm{C}$ por $48 \mathrm{~h}$ para determinação de massa seca (Nakagawa, 1999). Os resultados foram expressos em miligramas por plântula.

O delineamento experimental utilizado foi inteiramente casualisado (DIC), constituído por sete tratamentos (lotes), com quatro repetições por tratamento. Os resultados foram submetidos ao teste de Tukey a $5 \%$ de probabilidade e os dados processados pelo programa SISVAR (Ferreira, 2008).

\section{RESULTADOS E DISCUSSÃO}

Os resultados de massa de mil sementes, teor de água, pureza dos lotes, a percentagem de sementes trincadas, manchadas e enrugadas, obtidos na caracterização dos lotes das sementes "salvas" e comerciais, são apresentados no Quadro 1.

A massa de mil sementes (Quadro 1) foi homogênea para a maioria das cultivares. Esses resultados estão de acordo com Vanzolini e Carvalho (2002), exceto para cultivar CD215 comercial que apresentou 
Quadro 1 - Caracterização inicial (valores médios) de três lotes de sementes salvas e quatro lotes comerciais quanto à massa de mil sementes (Ms), teor de água (Ta), sementes puras (Sp), sementes trincadas (St), sementes manchadas (Sm) e sementes enrugadas (Se)

\begin{tabular}{|c|c|c|c|c|c|c|}
\hline \multirow{2}{*}{ Cultivares } & Ms & TA & $\mathrm{Sp}$ & $* \mathrm{St}$ & *Sm & $* \mathrm{Se}$ \\
\hline & (g) & \multicolumn{5}{|c|}{ 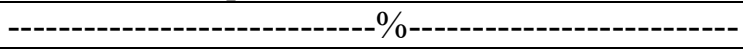 } \\
\hline \multicolumn{7}{|l|}{ Salvas } \\
\hline V-Top RR & 158,0 & 9,6 & $89 \mathrm{a}$ & 5 & $3 \mathrm{~cd}$ & 3 \\
\hline V-Max RR & 166,7 & 9,8 & $92 \mathrm{abc}$ & 4 & $1 \mathrm{bc}$ & 3 \\
\hline V-Max & 146,9 & 10,2 & $89 \mathrm{a}$ & 4 & $4 \mathrm{~d}$ & 3 \\
\hline \multicolumn{7}{|l|}{ Comerciais } \\
\hline V-Top RR & 176,6 & 9,4 & $90 \mathrm{ab}$ & 5 & $1 \mathrm{ab}$ & 4 \\
\hline V-Max RR & 174,0 & 10,1 & $93 \mathrm{bc}$ & 4 & $0 \mathrm{a}$ & 3 \\
\hline CD-215 RR & 163,5 & 9,6 & $92 \mathrm{abc}$ & 3 & $2 \mathrm{~cd}$ & 3 \\
\hline $\mathrm{CD}-215$ & 126,4 & 9,3 & $94 \mathrm{c}$ & 3 & $1 \mathrm{bc}$ & 2 \\
\hline CV $(\%)$ & & & 1,6 & 14,2 & 27,0 & 24,1 \\
\hline $\mathrm{Fc}$ & & & $6,6^{*}$ & $2,5^{\mathrm{ns}}$ & $14,5^{*}$ & $0,8^{\text {ns }}$ \\
\hline
\end{tabular}

Médias seguidas de letras na coluna, diferem entre si, pelo teste de Tukey ao nível de $5 \%$ de probabilidade. Fc não significativons; significativo* *Variáveis apresentadas com os dados originais com os valores transformados por $\sqrt{ } \mathrm{x}$ para análise estatística. CV= Coeficiente de variação.

valor mais baixo, com apenas 126,4 g devido à semente ser de peneira $5,5 \mathrm{~mm}$, enquanto as demais eram de $6,5 \mathrm{~mm}$. O teor de água encontrado variou entre 9,3 e 10,2\%, valores considerados normais em sementes que estão armazenadas antes da semeadura, de acordo com Santos et al. (2011) e Forti et al. (2010), que observaram teor de água entre lotes de 8,8 a $9,2 \%$ e de 10,2 a $10,8 \%$ em sementes de soja, respectivamente em ambiente não controlado.

Nota-se que quando se trata da pureza das sementes (Quadro 1), os lotes comerciais se destacaram na avaliação, diferindo estatisticamente dos lotes de sementes salvas, sobressaindo-se a cultivar CD215 com 94\% de pureza. As cultivares V-TopRR e V-Max "salvas" apresentaram o pior índice, 89\%, observando que quanto maior o grau de pureza da semente, menor será a percentagem de sementes com avarias, impróprias para a semeadura. As sementes trincadas (Quadro 1) foram as que apresentaram os maiores valores entre os danos observados.

De acordo com Carraro e Peske (2005), os principais danos encontrados nas sementes, são danos mecânicos e a deterioração por umidade, sendo estes as principais causas da baixa qualidade de alguns lotes de sementes de soja. Ainda, sementes expostas às condições de campo, por período prolongado, após o estádio $\mathrm{R} 8$, apresentam redução na qualidade (Holtz e Reis, 2013).

No entanto, entre os lotes, não se observou diferença estatística para sementes trincadas, da mesma forma que para sementes enrugadas. Quanto à percentagem de sementes manchadas, as sementes "salvas" apresentaram valores maiores que as comerciais, a Vmax salva com $4 \%$, enquanto a V-maxRR comercial não apresentou esse tipo de dano. Entre os lotes estudados, as sementes trincadas apresentaram altos índices de danos, indicando que os cuidados no campo, com a regulagem da colhedora e com o teor de água na hora da colheita devem ser criteriosos, pois ocasionam esse tipo dano. Vale ressaltar que as sementes "salvas" foram beneficiadas em mesa densimétrica, procedimento esse que deve ter melhorado a pureza inicial.

Para determinar o vigor foram realizados os testes de envelhecimento acelerado, teste de frio, emergência em areia, índice de velocidade de emergência e condutividade elétrica (Quadro 2). Para certificação de que as sementes embeberam no teste de envelhecimento acelerado, foi determinado o teor de água após as sementes ficarem na câmara de envelhecimento. Observa-se que o teor de água ficou entre 25,5 a $28 \%$ (Quadro 2) de acordo resultados encontrados por Santos et al. (2011) e Vanzolini e Carvalho (2002), indicando que o processo de envelhecimento foi conduzido de forma adequada.

Pode-se identificar lotes de baixo e alto vigor indicados pelos números 1 e 2 (Quadro 2), respectivamente, classificação esta adotada no presente estudo. O teste de envelhecimento acelerado foi o único 
Quadro 2 - Valores médios das variáveis dos testes de vigor de três lotes de sementes salvas e quatro lotes comerciais quanto ao teor de água inicial (TAi), teor de água após envelhecimento acelerado (TEA), envelhecimento acelerado (EA), teste de frio (Tf), germinação em papel (Gp), germinação em areia (Ea), índice de velocidade de emergência (IVE) e condutividade elétrica (CE)

\begin{tabular}{|c|c|c|c|c|c|c|c|c|}
\hline \multirow{2}{*}{ Cultivares } & TAi & TEA & EA & $\mathrm{Tf}$ & Gp & $\mathrm{Ea}$ & IVE & $\mathrm{CE}$ \\
\hline & \multicolumn{6}{|c|}{ 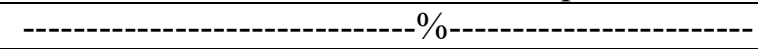 } & P./dia & $\mu \mathrm{S} . \mathrm{cm}^{-1} \cdot \mathrm{g}^{-1}$ \\
\hline \multicolumn{9}{|l|}{ Salvas } \\
\hline${ }^{1} \mathrm{~V}$-Top RR & 9,6 & 26,1 & $50 \mathrm{c}$ & $73 \mathrm{abc}$ & $90 \mathrm{ab}$ & $90 \mathrm{abc}$ & $17 \mathrm{ab}$ & $57,5 \mathrm{ab}$ \\
\hline${ }^{1} \mathrm{~V}-\mathrm{Max} \mathrm{RR}$ & 9,8 & 26,5 & $34 \mathrm{~b}$ & $69 a b$ & $89 \mathrm{ab}$ & $95 \mathrm{bcd}$ & $18 \mathrm{abc}$ & $80,4 \mathrm{c}$ \\
\hline${ }^{2} \mathrm{~V}-\mathrm{Max}$ & 10,2 & 27,3 & $77 \mathrm{~d}$ & $85 \mathrm{bc}$ & $88 \mathrm{ab}$ & $88 \mathrm{ab}$ & $17 \mathrm{ab}$ & $56,4 \mathrm{a}$ \\
\hline \multicolumn{9}{|l|}{ Comerciais } \\
\hline${ }^{1} \mathrm{~V}$-Top RR & 9,4 & 25,5 & $21 \mathrm{ab}$ & $84 \mathrm{bc}$ & $94 \mathrm{~b}$ & $90 \mathrm{abc}$ & $17 \mathrm{ab}$ & $67,5 \mathrm{~b}$ \\
\hline${ }^{1} \mathrm{~V}-\mathrm{Max} \mathrm{RR}$ & 10,1 & 26,1 & $16 \mathrm{a}$ & $72 \mathrm{abc}$ & $89 \mathrm{ab}$ & $97 \mathrm{~cd}$ & $19 \mathrm{bc}$ & $63,2 \mathrm{ab}$ \\
\hline${ }^{1} \mathrm{CD}-215 \mathrm{RR}$ & 9,6 & 25,9 & $58 \mathrm{c}$ & $64 \mathrm{a}$ & $80 \mathrm{a}$ & $87 \mathrm{a}$ & $16 \mathrm{a}$ & $80,9 \mathrm{c}$ \\
\hline${ }^{2} \mathrm{CD}-215$ & 9,3 & 28,0 & $84 \mathrm{~d}$ & $88 \mathrm{c}$ & $97 \mathrm{~b}$ & $99 \mathrm{~d}$ & $20 \mathrm{c}$ & $64,3 \mathrm{ab}$ \\
\hline CV (\%) & & & 12,3 & 10,8 & 5,3 & 3,9 & 4,2 & 6,8 \\
\hline Fc & & & $77,9^{*}$ & $4,8^{*}$ & $4,9^{*}$ & $7,3^{*}$ & $8,2^{*}$ & $19,1^{*}$ \\
\hline
\end{tabular}

Médias seguidas de letras na coluna, diferem entre si, pelo teste de Tukey ao nível de $5 \%$ de probabilidade. Fc não significativons; significativo*. ${ }^{1}$ Lotes de sementes considerados com baixo vigor; ${ }^{2}$ Lotes de sementes considerados com alto vigor. $\mathrm{CV}=$ Coeficiente de variação.

que conseguiu separar estatisticamente os lotes de alto e baixo vigor. Valores encontrados no teste de envelhecimento acelerado estão de acordo com os de Schuab et al. (2002), os quais observaram diferença significativa entre as médias, diferenciando os lotes de alto e baixo vigor.

Nos testes de envelhecimento acelerado, de frio e condutividade elétrica, os lotes diferiram estatisticamente entre si, em cada teste. Observa-se que os lotes que apresentaram melhor potencial fisiológico nos três testes, foram as cultivares convencionais, V-Max salva e CD-215 comercial.

Em geral, tem-se verificado que teores de água muito baixos $(\leq 10 \%)$ ou muito altos $(\geq 17 \%)$ apresentam influência significativa nos resultados de condutividade elétrica. Logo, recomenda-se a uniformização dos teores de água dos lotes para uma faixa entre $10 \%$ e $17 \%$, antes da avaliação da condutividade elétrica (Hampton et al., 1992). Efeito maior tem sido observado quando o teor de água das sementes é muito baixo $(\leq 10 \%)$, causando aumento significativo nos resultados do teste para várias espécies. Os valores dos teores de água observados (Quadro 1) foram próximos a 10\%, sendo que a cultivar CD-215 e a V-max apresentaram o menor e o maior valor respectivamente de 9,3 e 10,2\%.

Verifica-se que no índice de velocidade de emergência (IVE), os valores diferiram estatisticamente entre os lotes (Quadro 2). Entretanto, foram próximos e não tiveram relação direta com os outros testes. Pode-se verificar que o teste confirma ser a cultivar CD-215 convencional e a CD-215RR, foi o melhor e pior potencial fisiológico respectivamente, entre os lotes estudadas. Vanzolini e Carvalho (2002) encontraram valores de IVE que variaram de 7,3 a 19,7, ao avaliarem nove lotes de semente de soja. Esses valores próximos de IVE (Quadro 2) são justificados pela pequena diferença de vigor entre os lotes. Diferindo dos dados da pesquisa realizada pelos autores citados, em que os lotes apresentavam grande diferença no potencial fisiológico. No entanto, o lote com maior potencial fisiológico 19,7 (Vanzolini e Carvalho 2002), foi semelhante ao da presente pesquisa.

De modo geral, os lotes de sementes "salvas" não diferiram dos lotes de sementes comerciais. Os lotes de sementes "salvas" e comerciais se enquadraram nas duas situações baixo e alto vigor (Quadro 2), indicados pelos números 1 e 2 , sendo assim, as diferentes formas de produção de sementes não interferiram no desempenho das sementes.

Nota-se que no teste de germinação em substrato de papel e emergência em areia (Quadro 2), os lotes de sementes ficaram com a qualidade acima do mínimo de $80 \%$, valor exigido para comercialização como sementes, conforme determinado pela Secretaria da Agricultura e do Abastecimento (Paraná, 1986) e a Lei no 10.711 de 5 de agosto de 2003 (Brasil, 2003) evidenciando que todos os lotes avaliados estavam de acordo com as normas atuais para a comercialização de sementes. Os resultados obtidos 
Quadro 3 - Valores médios das variáveis a partir do teste de crescimento de plântulas de três lotes de semente salvas e quatro lotes comerciais quanto à massa fresca (MF), massa seca (MS), comprimento da parte aérea (CA) e comprimento de raiz $(C R)$

\begin{tabular}{|c|c|c|c|c|c|c|}
\hline \multirow[b]{2}{*}{ Cultivares } & \multicolumn{3}{|c|}{ Parte Aérea } & \multicolumn{3}{|c|}{ Raiz } \\
\hline & $\begin{array}{l}* \mathrm{MF} \\
(\mathrm{mg})\end{array}$ & $\begin{array}{l}\text { *MS } \\
(\mathrm{mg})\end{array}$ & $\begin{array}{l}{ }^{*} \mathrm{CA} \\
(\mathrm{mm})\end{array}$ & $\begin{array}{l}* \mathrm{MF} \\
(\mathrm{mg})\end{array}$ & $\begin{array}{l}* \mathrm{MS} \\
(\mathrm{mg})\end{array}$ & $\begin{array}{l}{ }^{*} \mathrm{CR} \\
(\mathrm{mm})\end{array}$ \\
\hline \multicolumn{7}{|l|}{ Salvas } \\
\hline${ }^{1} \mathrm{~V}$-Top RR & $459,5 \mathrm{~b}$ & 28,8 & $92 \mathrm{~b}$ & $240,5 \mathrm{ab}$ & $11,1 \mathrm{bc}$ & $108 \mathrm{a}$ \\
\hline${ }^{1}$ V-Max RR & $320,0 \mathrm{ab}$ & 31,2 & $61 \mathrm{ab}$ & $192,0 \mathrm{ab}$ & $13,5 \mathrm{c}$ & $111 \mathrm{a}$ \\
\hline${ }^{2} \mathrm{~V}-\mathrm{Max}$ & $405,3 \mathrm{ab}$ & 27,7 & $70 \mathrm{ab}$ & $261,0 \mathrm{ab}$ & $9,3 \mathrm{abc}$ & $157 \mathrm{ab}$ \\
\hline \multicolumn{7}{|l|}{ Comerciais } \\
\hline${ }^{1} \mathrm{~V}$-Top RR & $244,5 \mathrm{a}$ & 14,9 & $44 \mathrm{a}$ & $167,8 \mathrm{a}$ & $6,4 \mathrm{ab}$ & $105 \mathrm{a}$ \\
\hline${ }^{1} \mathrm{~V}-\mathrm{Max} R R$ & $252,0 \mathrm{ab}$ & 17,7 & $54 \mathrm{ab}$ & $183,3 \mathrm{ab}$ & $5,2 \mathrm{a}$ & $114 \mathrm{a}$ \\
\hline${ }^{1} \mathrm{CD}-215 \mathrm{RR}$ & $277,5 \mathrm{ab}$ & 16,5 & $58 \mathrm{ab}$ & $203,0 \mathrm{ab}$ & $12,2 \mathrm{c}$ & $125 a b$ \\
\hline${ }^{2} \mathrm{CD}-215$ & $418,8 \mathrm{ab}$ & 27,6 & $83 \mathrm{~b}$ & $284,8 \mathrm{~b}$ & $14,3 \mathrm{c}$ & $174 \mathrm{~b}$ \\
\hline CV (\%) & 14,2 & 23,2 & 14,7 & 11,2 & 12,0 & 9,8 \\
\hline $\mathrm{Fc}$ & $3,9^{*}$ & $1,8^{\mathrm{ns}}$ & $3,4^{*}$ & $3,4^{*}$ & $9,2^{*}$ & $4,6^{*}$ \\
\hline
\end{tabular}

Médias seguidas de letras na coluna, diferem entre si, pelo teste de Tukey ao nível de $5 \%$ de probabilidade. Fc não significativons; significativo* ${ }^{*}$ Variáveis apresentadas com os dados originais com os valores transformados por $\sqrt{ } \mathrm{x}$ para análise estatística. ${ }^{1}$ Lotes de sementes considerados com baixo vigor; ${ }^{2}$ Lotes de sementes considerados com alto vigor. CV= Coeficiente de variação.

nesta pesquisa são próximos aos obtidos nos testes conduzidos por (Nakagawa, 1999; Forti et al., 2010). No entanto, quanto maior a germinação de um lote de sementes, melhor será a uniformidade de emergência no campo, garantido estande mais adequado, podendo-se esperar melhor produção. Sendo assim, os lotes diferiram estatisticamente nestes testes, com destaque para a cultivar CD-215 comercial com 97 e $99 \%$ de germinação e emergência em areia, respectivamente. Entre os lotes de sementes "salvas" e comerciais, não houve diferença.

A massa fresca da parte aérea e da raiz (Quadro 3) apresentou diferença significativa entre os lotes, conforme valores estabelecidos por Vanzolini e Carvalho (2002). Pode-se identificar que a cultivar CD-215 comercial e a V-TopRR "salva" pelo produtor, foram as que apresentaram o maior potencial fisiológico neste teste.

A massa seca da parte aérea não diferiu estatisticamente entre os lotes avaliados, o que não ocorreu com a massa seca de raiz, diferindo estatisticamente entre os lotes. A cultivar V-maxRR "salva", a CD-215RR e CD-215 comercial foram as que apresentaram os melhores resultados.

Quanto ao comprimento da parte aérea e comprimento de raiz, ambos foram significativos, com destaque para a cultivar CD-215 comercial, a qual apresentou maiores valores de parte aérea e de raiz que os demais lotes avaliados. Quando se observa os lotes de sementes "salvas" e comerciais, nos itens avaliados (Quadro 3), observa-se que não houve diferença no potencial fisiológico entre os sistemas de produção, de sementes "salvas" e comerciais.

Os lotes de baixo e alto vigor foram indicados pelos números 1 e 2, respectivamente (Quadro 3). Observa-se que o teste que define os lotes de baixo e alto vigor foi o de comprimento de raiz, apresentando valores estaticamente diferentes entre si. Os lotes da V-Max e CD-215 convencionais apresentaram, superiores no potencial fisiológico que as Roundup Ready (RR) de acordo com Carvalho et al. (2012), que observaram que as sementes de soja convencional CD - 206 têm potencial fisiológico superior em relação às da sua derivada transgênica. Pode-se observar ainda, que a CD-215 convencional não apresentou diferença significativa das demais, apenas na massa seca da parte aérea, sendo superior em todos os outros testes, isso provavelmente ocorreu, pois a semente deste lote era de peneira $5,5 \mathrm{~mm}$, enquanto os demais eram de $6,5 \mathrm{~mm}$.

Sementes que apresentam melhor potencial fisiológico, suportam melhor as condições adversas no campo (Lopes et al., 2002), como excesso ou falta de chuva após a semeadura, e tornam-se menos suscetíveis ao ataque de pragas na fase inicial do desenvolvimento. Outro fator importante é a uniformidade e o rápido desenvolvimento do estante, dificultando o aparecimento de plantas invasoras. Sementes com alto vigor proporcionam maior 
Quadro 4 - Valores médios das variáveis a partir do teste de emergência em areia de três lotes de semente salvas e quatro lotes comerciais quanto à massa fresca (MF), massa seca (MS), comprimento da parte aérea (CA) e comprimento de raiz $(C R)$

\begin{tabular}{|c|c|c|c|c|c|c|}
\hline \multirow[b]{2}{*}{ Cultivares } & \multicolumn{3}{|c|}{ Parte Aérea } & \multicolumn{3}{|c|}{ Raiz } \\
\hline & $\begin{array}{c}\text { MF } \\
(\mathrm{mg})\end{array}$ & $\begin{array}{c}\mathrm{MS} \\
(\mathrm{mg})\end{array}$ & $\begin{array}{c}\mathrm{CA} \\
(\mathrm{mm})\end{array}$ & $\begin{array}{c}\mathrm{MF} \\
(\mathrm{mg})\end{array}$ & $\begin{array}{c}* \mathrm{MS} \\
(\mathrm{mg}) \\
\end{array}$ & $\begin{array}{c}\mathrm{CR} \\
(\mathrm{mm})\end{array}$ \\
\hline \multicolumn{7}{|l|}{ Salvas } \\
\hline V-Top RR & $617,7 \mathrm{c}$ & 36,0 & $201 \mathrm{c}$ & $267,3 \mathrm{bc}$ & 9,5 & $119 \mathrm{a}$ \\
\hline V-Max RR & $547,8 \mathrm{ab}$ & 31,3 & $179 a b$ & $235,8 \mathrm{ab}$ & 9,3 & $137 \mathrm{ab}$ \\
\hline V-Max & $526,3 \mathrm{ab}$ & 30,3 & $164 \mathrm{a}$ & $252,7 \mathrm{ab}$ & 9,7 & $141 \mathrm{ab}$ \\
\hline \multicolumn{7}{|l|}{ Comerciais } \\
\hline V-Top RR & $565,0 \mathrm{abc}$ & 29,5 & $201 \mathrm{c}$ & $228,0 \mathrm{ab}$ & 8,3 & $129 a b$ \\
\hline V- Max RR & $538,7 \mathrm{ab}$ & 28,7 & $190 \mathrm{bc}$ & $212,0 \mathrm{a}$ & 10,3 & $126 \mathrm{ab}$ \\
\hline CD-215 RR & $566,5 \mathrm{bc}$ & 27,8 & $187 \mathrm{bc}$ & $308,5 \mathrm{c}$ & 12,5 & $167 \mathrm{~b}$ \\
\hline CD - 215 & $502,0 \mathrm{a}$ & 28,0 & $193 \mathrm{bc}$ & $272,8 \mathrm{bc}$ & 12,5 & $154 \mathrm{ab}$ \\
\hline CV (\%) & 5,1 & 12,2 & 4,7 & 7,9 & 28,2 & 13,8 \\
\hline $\mathrm{Fc}$ & $6,8^{*}$ & $2,4^{\mathrm{ns}}$ & $8,9^{*}$ & $10,4^{*}$ & $0,5^{\mathrm{ns}}$ & $3,1^{*}$ \\
\hline
\end{tabular}

Médias seguidas de letras na coluna, diferem entre si, pelo teste de Tukey ao nível de $5 \%$ de probabilidade. Fc não significativons; significativo* * Variáveis apresentadas com os dados originais com os valores transformados por $\sqrt{\square}$ para análise estatística. CV= Coeficiente de variação.

produtividade (Scheeren et al., 2010), sendo o que produtor espera no final da safra.

Os resultados de massa fresca e seca e comprimento da parte aérea e raiz do teste de comprimento de raízes e parte aérea das plântulas (Quadro 4), realizado a partir do teste de emergência em areia foram semelhantes aos obtidos por Schuab et al. (2002), quando avaliaram as plântulas, após o teste de emergência em campo.

Na determinação de massa seca da parte aérea não se encontra diferença estatística entre os lotes estudados, o que também foi observado no teste de crescimento de plântulas (Quadro 3). Quanto à massa fresca da parte aérea, os lotes diferiram estatisticamente entre si, sendo que a cultivar V-Top RR salva e a CD - 215 comerciais demonstraram o melhor e pior potencial fisiológico, respectivamente. As demais cultivares foram estatisticamente iguais. Quanto ao comprimento da parte aérea, a cultivar V-top RR salva e a V-top RR foram estatisticamente melhores que as demais cultivares. A V-max salva apresentou o menor potencial fisiológico.
Quanto à massa fresca de raiz os lotes diferiram estatisticamente entre si, com destaque para a cultivar CD-215 RR comercial, superior às demais (Quadro 4). Resultado semelhante foi observado para o comprimento de raiz, que apresentou maior massa fresca, devido ao seu maior comprimento.

\section{CONCLUSÕES}

1. Tanto sementes "salvas" quanto comerciais podem apresentar alto ou baixo vigor, o que depende de outros fatores e não apenas do modo de produção;

2. As sementes comerciais apresentaram maior pureza que as sementes "salvas";

3. As sementes de cultivares de soja convencionais apresentaram potencial fisiológico superior que as sementes de soja Roundup Ready (RR);

4. O emprego de sementes "salvas" (para consumo próprio) não deve ser estimulado, já que não conta com as fiscalizações habituais e necessárias para a garantia da qualidade. 


\section{REFERÊNCIAS BIBLIOGRÁFICAS}

Barros, A.R.; Dias, M.C.L.L.; Cicero, S.M e Krzyzanowski, F.C. (1999) - Teste de frio. In: Krzyzanowski, F.C.; Vieira, R.D. e França Neto, J.B. (Eds.) - Vigor de sementes: conceitos e testes. ABRATES, 218 p.

Bervald, C.M.P; Mendes, C.R.; Timm, F.C; Moraes, D.M.; Barros, A.C.S.A e Peske, S.T. (2010) - Desempenho fisiológico de sementes de soja de cultivares convencional e transgênica submetidas ao glifosato. Revista Brasileira de Sementes, vol. 32, n. 2, p. 09-18. http://dx.doi.org/10.1590/S0101-31222010000200001

Brasil (2003) - Lei no 10.711 de 5 de agosto de 2003. Dispõe sobre o sistema nacional de sementes e mudas e dá outras providências. Diário Oficial da União, Brasília - DF, Seção 1. p. 1, 6 de agosto de 2003.

Brasil (2009) - Regras para análise de sementes. Brasília, Ministério da Agricultura, Pecuária e Abastecimento/ ACS. 398 p.

Carraro, I.M. e Peske, S.T. (2005) - Uso de semente de soja no estado do Paraná. Revista Brasileira de Sementes, vol. 27, n. 2, p. 75-80. http://dx.doi.org/10.1590/S0101-31222005000200011

Carvalho, T.C.; Grzybowski, C.R.S.; Ohlson, O.C. e Panobianco, M. (2012) - Comparação da qualidade fisiológica de sementes de soja convencional e de sua derivada transgênica. Revista Brasileira de Sementes, vol. 34, n. 1 p. 164-170. http://dx.doi.org/10.1590/S0101-31222012000100020

Carvalho, L.F.; Sediyama, C.S.; Reis, M.S.; Dias, D.C.F.S. e Moreira, M.A. (2009) -Influência da temperatura de embebição da semente de soja no teste de condutividade elétrica para avaliação da qualidade fisiológica. Revista Brasileira de Sementes, vol. 31, n. 1, p. 9-17. http://dx.doi.org/10.1590/S0101-31222009000100001

Ferreira, D.F. (2008) - SISVAR: Um programa para análises e ensino de estatística. Revista Científica Symposium, vol. 6, n. 2, p. 36-41.

Forti, V.A.; Cicero, S.M. e Pinto, T.L.F. (2010) - Avaliação da evolução de danos por "umidade" e redução do vigor em sementes de soja, cultivar TMG113-RR, durante o armazenamento, utilizando imagens de raios x e testes de potencial fisiológico. Revista Brasileira de Sementes, vol. 32, n. 3, p. 123-133. http://dx.doi. org/10.1590/S0101-31222010000300014

Furlaneto, F.B.; Reco, P.C.; Kanthack, R.A.D.; Esperancini, M.S.T. e Ojima, A.L.R.O. (2008) - Soja transgênica versus conencional: Estimativas de custos operacionais de produção na região do médio Paranapanema, Estado de São Paulo. Ciência e Agrotecnologia, vol. 32, n. 6, p. 1935-1940. http://dx.doi.org/10.1590/S141370542008000600037

Hampton, J.G.; Johnstone, K.A. e Eua-Umpon, V. (1992) - Bulk conductivity test variables for mungbean, soybean and French bean seed lots. Seed Science and Technology, vol. 20, n. 3, p. 677-686.

Holtz, V. e Reis, E.F. (2013) - Perdas na colheita mecanizada de soja: uma análise quantitativa e qualitativa. Revista Ceres, vol. 60, n. 3, p. 347-353. http://dx.doi.org/10.1590/S0034-737X2013000300007

Lima, E.V.; Crusciol, C.A.C.; Cavariani, C. e Nakagawa, J. (2009) - Características agronômicas, produtividade e qualidade fisiológica da soja "safrinha" sob semeadura direta, em função da cobertura vegetal e da calagem superficial. Revista Brasileira de Sementes, vol. 31, n. 1, p. 69-80. http://dx.doi.org/10.1590/S010131222009000100008.

Lopes, J.C.; Martins-Filho, S.; Tagliaferre, C. e Rangel, O.J.P. (2002) - Avaliação da qualidade fisiológica de sementes de soja produzidas em Alegre-ES. Revista Brasileira de Sementes, vol. 24, n. 1, p. 51-58. http:// dx.doi.org/10.1590/S0101-31222002000100008

Maguire, J.D. (1962) - Speed of germination-aid in selection and evaluation for seedling emergence and vigor. Crop Science, vol. 2, n. 1, p. 176-177. http://dx.doi.org/10.2135/cropsci1962.0011183X000200020033x

Marcondes, M.C.; Miglioranza, E. e Fonseca, I.C.B (2005) - Danos mecânicos e qualidade fisiológica de semente de soja colhida pelo sistema convencional e axial. Revista Brasileira de Sementes, vol. 27, n. 2, p. 125129. http://dx.doi.org/10.1590/S0101-31222005000200018

Marcos Filho, J. (1999) - Teste de envelhecimento acelerado. In: Krzyzanowski, F.C.; Vieira, R.D. e França Neto, J.B. (Eds.) - Vigor de sementes: conceitos e testes. Londrina: ABRATES, p. 1-24.

Milani, M.; Menezes, N.L. e Lopes, S.J. (2012) - Teste de condutividade elétrica para avaliação do potencial fisiológico de sementes de canola. Revista Ceres, vol. 59, n. 3, p. 374-379. http://dx.doi.org/10.1590/S0034737X2012000300012

Moterle, L.M.; Santos, R.F.; Scapim, C.A.; Braccini, A.L.; Bonato, C.M. e Conrado, T. (2011) - Efeito de biorregulador na germinação e no vigor de sementes de soja. Revista Ceres, vol. 58, n. 5, p. 651-660.

Nakagawa, J. (1999) - Testes de vigor baseados no desempenho das plântulas. In: Krzyzanowski, F.C.; Vieira, 
R.D. e França Neto, J.B. (Eds.) - Vigor de sementes: conceitos e testes. Londrina: ABRATES, p. 1-24.

Oliveira, A.C.S.; Martins, G.N.; Silva, R.F. e Vieira, H.D. (2009) - Testes de vigor em sementes baseados no desempenho de plântulas. Revista Cientifica Internacional. vol. 2, n. 4, p. 1-21.

Paraná (1986) - Secretaria de Estado da Agricultura e do Abastecimento - SEAB. Resolução nº 51, de 1986. Estabelece as normas para produção de sementes no estado.

Pinto, T.L.F.; Cicero, S.M. e Forti, V.A. (2007) - Avaliação de danos por umidade, em sementes de soja, utilizando a técnica da análise de imagens. Revista Brasileira de Sementes, vol. 29, n. 3, p. 31-38. http://dx.doi. org/10.1590/S0101-31222007000300004

Rigon, J.P.G.; Capuani, S.; Neto, J.F.B.; Rosa, G.M.; Wastowski, A.D. e Rigon, C.A.G. (2012) - Dissimilaridade genética e análise de trilha de cultivares de soja avaliada por meio de descritores quantitativos. Revista Ceres, vol. 59, n. 2, p. 233-240. http://dx.doi.org/10.1590/S0034-737X2012000200012

Santos, J.F.; Alvarenga, R.O.; Timóteo, T.S.; Conforto, E.C.; Filho, J.M. e Vieira, R.D. (2011) - Avaliação do potencial fisiológico de lotes de sementes de soja. Revista Brasileira de Sementes, vol. 33, n. 4, p. 743-751. http://dx.doi.org/10.1590/S0101-31222011000400016

Scheeren, B.R.; Teichertpeske, S.; Schuch, L.O.B. e Barros, A.C.A. (2010) - Qualidade fisiológica e produtividade de sementes de soja. Revista Brasileira de Sementes, vol. 32, n. 3, p. 35-41. http://dx.doi.org/10.1590/ S0101-31222009000100016

Schuab, S.R.P.; Braccini, A.L.; França Neto, J.B.; Scapim, C.A. e Meschede, D.K. (2002) - Utilização da taxa de crescimento das plântulas na avaliação do vigor de sementes de soja. Revista Brasileira de Sementes, vol. 24, n. 2, p. 90-95.

Sinício, R.; Bhering, M.C.; Vidigal, D.S. e Santos Dias, D.C.F. (2009) - Validação do aplicativo computacional SEEDSOLVE para previsão das perdas de germinação e vigor de sementes armazenadas. Revista Brasileira de Sementes, vol. 31, n. 2, p. 9-18. http://dx.doi.org/10.1590/S0101-31222009000200001

Silva, M.A.D.; Vieira, R.D. e Santos, J.M. (2008) - Influência do envelhecimento acelerado na anatomia da testa de sementes de soja, cv. Monsoy 8400. Revista Brasileira de Sementes, vol. 30, n. 2, p. 91-99. http://dx.doi. org/10.1590/S0101-31222008000200012

Torres, F.E.; David, G.V.; Teodoro, P.E.; Ribeiro, L.P.; Correa, C.G. e Luz Júnior, R.A. (2015) - Desempenho agronómico e dissimilaridade genética entre genótipos de soja. Revista de Ciências Agrárias, vol. 38, n. 1, p. 111-117.

Tozzo, G.A. e Peske, S.T. (2007) - Sementes de soja comerciais e salvas. Revista Brasileira de Sementes, vol. 30, n. 2, p. 12-18. http://dx.doi.org/10.1590/S0101-31222008000200002

Vanzolini, S. e Carvalho, N.M. (2002) - Efeito do vigor de sementes de soja sobre o seu desempenho em campo. Revista Brasileira de Sementes, vol. 24, n. 1, p. 33-41.

Vieira, R.D. e Krzyzanowski, F.C. (1999) - Teste de condutividade elétrica. In: Krzyzanowski, F.C.; Vieira, R.D. \& França Neto, J.B. (Eds.) - Vigor de sementes: conceitos e testes. Londrina, ABRATES. p. 4.1-4.26. 